\title{
Evaluation of effecting factors on oil recovery using the desirability function
}

\author{
Suparit Tangparitkul ${ }^{1}$
}

Received: 7 September 2017 / Accepted: 20 January 2018 / Published online: 8 February 2018

(c) The Author(s) 2018. This article is an open access publication

\begin{abstract}
The new method to evaluate the contribution of the related factors to the oil recovery is proposed by using the desirability model. The related factors are re-scaled and combined to be a single parameter in order to correlate with an indicator of oil recovery. The correlated result could be able to predict a trend of the factors and oil recovery as an empirical approach if a good correlation is achieved. Three published works of the coreflooding experiments are examined the effectivenesses and limitations of the proposed model. The analysed plots of desirability and the oil recovery imply an insight into the oil recovery mechanisms by indicating the dominant factors. The results meet a good agreement with the published works. Although the dominant factors are indicated and the correlation trend is able to be determined, the accuracy of the proposed method needs a high number of data sets to increase the statistical reliability.
\end{abstract}

Keywords Reservoir engineering $\cdot$ Oil production $\cdot$ Enhanced oil recovery $\cdot$ Desirability function $\cdot$ Rock and fluid properties

\section{Introduction}

Generally, a number of related properties both petroleum fluids and reservoir rock influence or contribute to the oil recovery and its production. These related properties or the oil recovery factors are hardly able to indicate that which of them is relatively the main contributor to recover the oil. For example, the oil-aqueous interfacial tension (IFT) and the contact angle $(\theta)$ are the main factors used widely to describe the oil recovery mechanism despite they are physically related. The contact angle $(\theta)$ is theoretically governed by surface energies of three interfaces or so-called the interfacial tensions according to Young's equation (Young 1805). Hence, the IFTs and the contact angle $(\theta)$ are not independent to each other or to the oil recovery, leading to the question that which factor is really the main contributor to recover the oil and how to distinguish such the related factors.

Having a number of considering factors could bring a problem of vague conclusion in the oil recovery study or it

Suparit Tangparitkul

suparit.t@cmu.ac.th

1 Department of Mining and Petroleum Engineering, Chiang Mai University, Chiang Mai 50200, Thailand could be even a misconclusion about the considering factors. This mistake would result in an ineffective oil production due to its wrong design. For example, the nanofluids of polymer-coated was used in the coreflooding experiment to evaluate the recovery mechanism studied by Choi et al. (2017). The study only reported the oil-aqueous IFT and fluids viscosity as the properties related to the coreflooding test without the surface wettability measurement (e.g. contact angle). However, the authors concluded that the wettability alteration was a mechanism to enhance oil recovery highlighting the nanofluids as the potential injection agent. In this case, the governing mechanism would possibly be the decrease in the mobility ratio (oil to water viscosity) rather than the change in the oil-aqueous IFT because the oil-aqueous IFT showed a negative impact on the oil recovery (i.e. the oil-aqueous IFT increased as the nanofluids were added). Thus, the method to separate the contribution of each factor is needed to emphasise the fundamental insight into the study of oil recovery.

Recently, Nikolaev et al. (2017) introduced to use the desirability function to evaluate the effectiveness of four industrial solvents for enhanced oil recovery (EOR). By combining two quantities of the IFT and residual (trapped) oil into one quantity, the authors can obtain the most potential solvents to recover the oil. Although the desirability

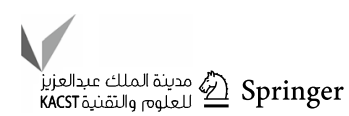


function is widely used in various disciplines (e.g. engineering, pharmaceutical, food science and process, etc.), it have not been well documented and applied in petroleum engineering (e.g. the oil recovery) and it has not been reported yet to separate the contribution of the related factors to determine the dominant one.

Unlike Nikolaev et al. (2017), the desirability function is proposed in this paper to integrate the effecting factors and also separate the factors' contribution. The aim is to evaluate the factors' effectiveness leading to understand the insight into the fundamental of the oil recovery mechanism. The application of the proposed method is able to consider other quantity (e.g. permeability decline) rather than the oil recover.

The desirability model and analysis method are presented in the next section including some specific terminology with details. The proposed model is applied to three published works to demonstrate its use with the details of the calculations. The effectiveness and limitation of the model are then discussed followed by the conclusion.

\section{Desirability model}

\section{Terminology}

The oil productivity could be assessed by a number of quantities, such as the volume of oil recovery, recovery factor, reservoir pressure drop, permeability decline, etc. These quantities are typically used to evaluate the oil recovery techniques and hence the best technique is subsequently recommended to apply in the field production. These assessing parameters, so-called "indicators" hereafter, are normally affected by a number of related factors. The "factors" could be collectively allocated based on either theoretical equations or reported studies. For example, on the study of oil flow in the reservoir, the flow of oil phase $\left(q_{\mathrm{o}}\right)$ as an indicator depends on relative permeability of oil phase $\left(k_{r o}\right)$, flow sectional area $(A)$, pressure drop $(\Delta P)$, oil viscosity $\left(\mu_{\mathrm{o}}\right)$ and reservoir distance $(L)$ according to Darcy's law;

$q_{o}=\frac{k_{r o} A \Delta P}{\mu_{o} L}$

In this example, all the factors [consisting of relative permeability of oil phase $\left(k_{r o}\right)$, flow sectional area $(A)$, pressure drop $(\Delta P)$, oil viscosity $\left(\mu_{\mathrm{o}}\right)$ and reservoir distance $\left.(L)\right]$ are assigned as the affecting factors to the oil flow (an assessing indicator).

Affecting factor can be classified into two types according to its desirability on the assessing indicator. The factor resulting in favour for the indicator (i.e. promoting the indicator) is defined as the desirable factor. On the other hand, the factor resulting in unfavour for the indicator (i.e. eradicating the indicator) is defined as the undesirable factor. According to the example, the higher the relative permeability of oil phase $\left(k_{r o}\right)$, the higher the oil flow $\left(q_{\mathrm{o}}\right)$. Thus, the relative permeability of oil phase $\left(k_{r \mathrm{o}}\right)$ is defined as a desirable factor to the oil flow $\left(q_{\mathrm{o}}\right)$. Besides, the higher the oil viscosity $\left(\mu_{\mathrm{o}}\right)$, the lower the oil flow $\left(q_{\mathrm{o}}\right)$. Then, the oil viscosity $\left(\mu_{\mathrm{o}}\right)$ is defined as an undesirable factor to the oil flow $\left(q_{\mathrm{o}}\right)$.

\section{Desirability function}

The desirability is the summation of all considering factors or criterions (either desirable factor or undesirable factor) to be a single factor. This single combined factor is called the desirability $(D)$ and expressed:

$D=\left(\prod_{i=1}^{n} d_{i}\right)^{\frac{1}{n}}=\sqrt[n]{d_{1} d_{2} \cdots d_{n}}$

where $d_{i}$ is the desirability function of the factor $i$ (individual desirability) and $n$ is the quantity of the affecting factors that are considered to affect the indicator.

The Harrington's function (Harrington 1965) is proposed to use as a desirability function (see Fig. 1);

$d_{i}=e^{-e^{-X_{i}}}$

where $X_{i}$ is the factor fraction depending on its desirability:

for desirable factor,

$X_{i}^{D}=\frac{S_{i}-S_{0}}{S_{1}-S_{0}}$

and for undesirable factor,

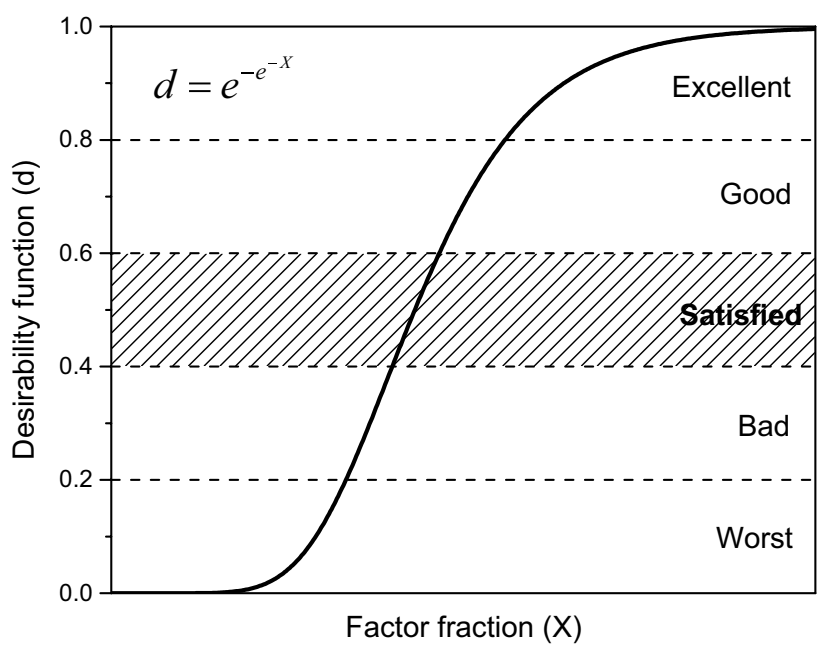

Fig. 1 The Harrington's function used as a desirability function $(d)$ 
$X_{i}^{U}=\frac{S_{0}-S_{i}}{S_{1}-S_{0}}$

Here $S_{i}$ is factor value, $S_{0}$ is lower limit value of the satisfied interval and $S_{1}$ is upper limit value of the satisfied interval. The definition of $S_{0}, S_{1}$ and the satisfied interval are discussed in the next section.

\section{Desirability scale}

The relation between the desirability function $\left(d_{i}\right)$ and the factor fraction $\left(X_{i}\right)$ is divided sectionally as the desirability scale, see Fig. 1. The scale of desirability emphasises a relationship between the affecting factor via factor fraction $\left(X_{i}\right)$ and the desirability function by the intervals of the desirable degree. The desirable degrees can be consecutively divided as excellent, good, satisfied, bad and worst degrees. In Fig. 1, the desirable degrees are assigned to the intervals with its fraction on the scale (e.g. $0.40-0.60$ for the satisfied interval).

The satisfied interval is the middle interval having the lower and upper limit values ( $S_{0}$ and $S_{1}$, respectively) as defined in Eqs. (4) and (5). Each affecting factor either desirable or undesirable needs to be assigned its value range reasonably according to its typical quantity or conventional magnitude of the particular study. The assigned value range of the factor allows the lower and the upper limit values $\left(S_{0}\right.$ and $S_{1}$ ) can be calculated.

\section{Model application to experiments and discussions}

The desirability model is demonstrated in this section to analyse the mechanistic coreflooding experiments published in the literature. The analysis shows the relationship between the desirability of related factors and the indicator of the oil recovery. Both individual desirability and combined desirability are used to indicate the domination of each effecting factor on the oil recovery (i.e. the dominant factor on the indicator). The result could be extended to predict a trend of the factors-and-indicator relation potentially if a good correlation is achieved.

The selected published works are examined the proposed model consisting of three coreflooding tests: Almansour et al. (2017) studied the polymer-low salinity injection in sandstone cores; Jeirani et al. (2013) reported 160 flooding data of sandpack as a function of the oil-water IFT; Zhou et al. (2000) conducted the systematic waterflooding in sandstones varying wettability, initial water saturation and permeability.

\section{Almansour et al. (2017)}

Almansour et al. (2017) conducted the fluid injection in sandstone cores (Berea and Bentheimer) whereas the polymer-augmented low salinity was introduced to use as a potential candidate fluid to enhance oil recovery. The cores permeability ranges $78-156 \mathrm{mD}$ and porosity ranges $20.1-22.9 \%$. The study used two fluids consisting of seawater and low salinity water.

Three affecting factors are chosen to evaluate its effectiveness on the oil recovery in form of the percentage of the original-oil-in-place (\%OOIP). The oil-aqueous IFT represents the interfacial responsiveness at the two immiscible phases of oil and the injection fluid. Aqueous contact angle $(\theta)$ represents the rock surface preference to be wetted by the fluid, so-called surface wettability. Fluid viscosity $(\mu)$ referred to flow mobility in the system (the mobility is the water viscosity to the oil viscosity ratio). These three factors are typically discussed in the EOR studies because they are known to associate in the EOR mechanisms (Anderson 1987; Hu et al. 2017; Jamaloei 2015; Jeirani et al. 2013; Jiang et al. 2016; Mason et al. 2010).

Table 1 shows the values of the affecting factors with its $\%$ OOIP from the coreflooding tests. The lowest and highest values of each affecting factor are assigned here to be the value range of that factor, and then it allows the lower and the upper limit values of the satisfied interval $\left(S_{0}\right.$ and $\left.S_{1}\right)$ to be calculated, see "Calculation of the lower and the upper limit values of the satisfied interval $\left(S_{0}\right.$ and $\left.S_{1}\right)$ " Appendix section. Since the oil-aqueous IFT and fluid viscosity $(\mu)$ are desirable factors which promote the oil recovery, their

Table 1 Evaluation of affecting factors (IFT, aqueous contact angle and oil viscosity) with its individual desirability $\left(d_{\mathrm{IFT}}, d_{\theta}\right.$ and $\left.d_{\mu}\right)$ and combined desirability $(D)$ for each fluid from the experiment of Almansour et al. (2017)

\begin{tabular}{|c|c|c|c|c|c|c|c|c|c|}
\hline \multirow[t]{2}{*}{ Core } & \multirow[t]{2}{*}{ Fluid } & \multicolumn{3}{|c|}{ Affecting factor } & \multicolumn{3}{|c|}{ Individual desirability $(d)$} & \multirow[t]{2}{*}{ Desirability $(D)$} & \multirow{2}{*}{$\begin{array}{l}\text { Indicator } \\
(\% \text { OOIP })\end{array}$} \\
\hline & & IFT $(\mathrm{mN} / \mathrm{m})$ & $\theta\left({ }^{\circ}\right)$ & $\mu(\mathrm{cP})$ & $d_{\mathrm{IFT}}$ & $d_{\theta}$ & $d_{\mu}$ & & \\
\hline \multirow[t]{2}{*}{ Benthimer } & Seawater & 53.0 & 70.1 & 0.73 & $9.51 \times 10^{-1}$ & $6.94 \times 10^{-1}$ & $9.51 \times 10^{-1}$ & $8.57 \times 10^{-1}$ & 92.6 \\
\hline & Low salinity & 44.4 & 65.1 & 0.64 & $6.18 \times 10^{-4}$ & $8.73 \times 10^{-1}$ & $6.18 \times 10^{-4}$ & $6.94 \times 10^{-3}$ & 90.3 \\
\hline \multirow[t]{2}{*}{ Berea } & Seawater & 53.0 & 90.3 & 0.73 & $9.51 \times 10^{-1}$ & $1.89 \times 10^{-9}$ & $9.51 \times 10^{-1}$ & $1.20 \times 10^{-3}$ & 57.0 \\
\hline & Low salinity & 44.4 & 75.4 & 0.64 & $6.18 \times 10^{-4}$ & $3.52 \times 10^{-1}$ & $6.18 \times 10^{-4}$ & $5.12 \times 10^{-3}$ & 67.0 \\
\hline
\end{tabular}


factor fractions are calculated according to Eq. (4). Unlike, the aqueous contact angle $(\theta)$ is an undesirable factor leading to use Eq. (5) because the higher oil recovery requires higher aqueous-wetted surface (lower aqueous contact angle). The calculation of factor fractions $\left(X_{i}\right)$ is shown in "Calculation of factor fractions $\left(X_{i}\right)$ " Appendix section. Consequently, Harrington's desirability function is calculated according to Eq. (3) for each factor. The individual desirabilities $\left(d_{i}\right)$ of each factor are combined as expressed in Eq. (2) obtaining the desirability $(D)$ and then the desirability $(D)$ is used to correlate with \%OOIP to assess the affecting factors. The individual and combined desirabilities $\left(d_{i}\right.$ and $\left.D\right)$ are reported in Table 1 and its calculations are also shown in "Calculation of individual and combined desirability $\left(d_{i}\right.$ and D)" Appendix section.

Interestingly, only the individual desirability of aqueous contact angle $\left(d_{\theta}\right)$ factor is able to imply the relationship with the oil recovery, shown in Fig. 2b. Such a positive or favourable trend to the indicator of the factor suggests that the contact angle $(\theta)$ might play a dominant role to recover the oil in the coreflooding experiments rather than other factors (IFT and fluid viscosity) which do not have such relationship at all (Fig. 2a and c).

Once all three individual desirabilities are combined, the oil recovery as an indicator is clearly correlated to the desirability $(D)$ shown in Fig. 3 with nonlinear curve relationship. The correlation implies that the oil recovery is affected by all three factors (IFT, $\theta$ and $\mu$ ) through the integrated desirability function. The relationship pronounces as a direct proportion. The higher the desirability $(D)$, the higher the oil recovery. It is noted that the $R^{2}$ of the fitting is not too high $\left(R^{2}=0.7212\right)$ because the curve is fitted from only 4 data. If a number of the data are massively collected, the fitting would be more obvious and the correlation would have greater reliability.

Additionally, the study is extended to investigate further on the individual factors. By separating one of the three factors from the combined desirability $(D)$, the only two duodesirabilities containing the aqueous contact angle factor $\left(d_{\mu, \theta}\right.$ and $\left.d_{\mathrm{IFT}, \theta}\right)$ are found linear relationship with the oil recovery, Fig. 4a and c. While the duo-desirability without contact angle factor $\left(d_{\mathrm{IFT}, \mu}\right)$ does not imply to any relationship due to its lack of contact angle contribution. The contact angle pronouncing dominantly on the oil recovery agrees with the previous mention of Fig. $2 b$ and was also concluded in the referred experimental work (Almansour et al. 2017) as the main recovery mechanism, so-called the wettability alteration.

\section{Jeirani et al. (2013)}

Triglyceride microemulsion was formulated to alter the oilaqueous IFT and then the different values of IFT were used
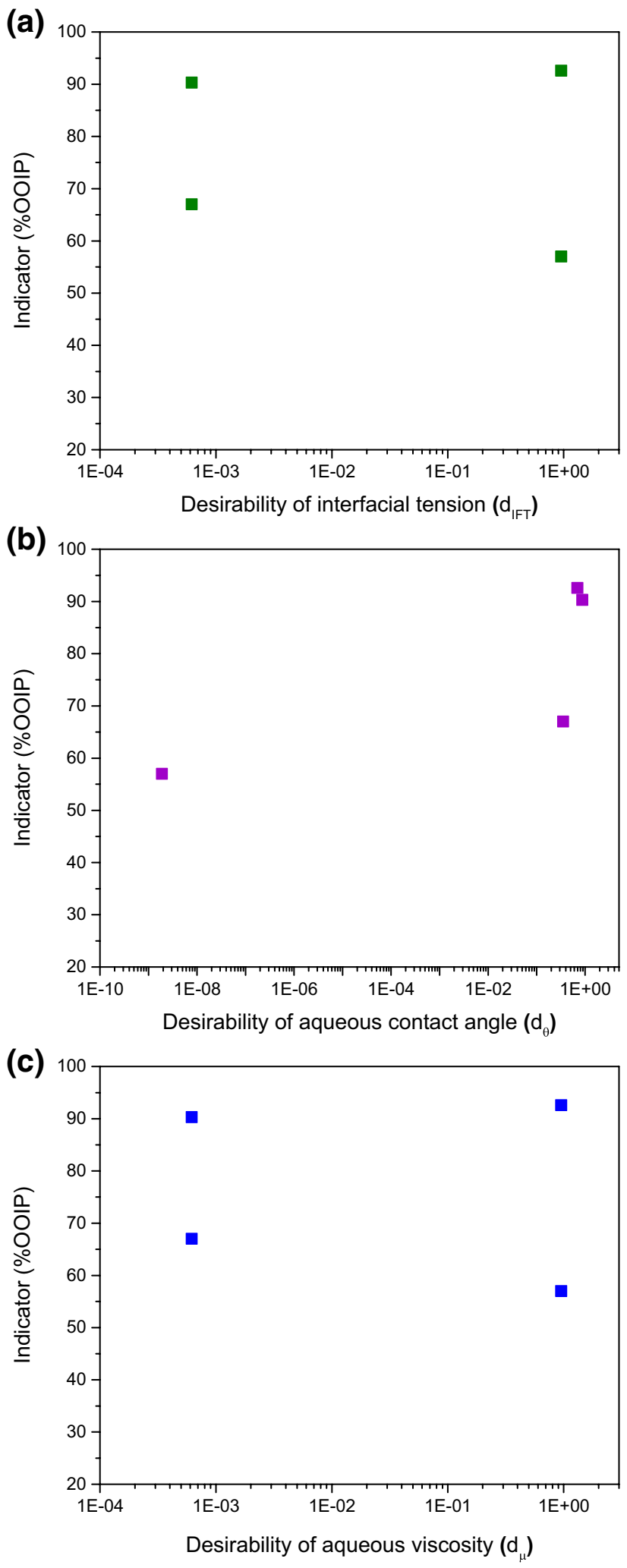

Fig. 2 Individual desirability $\left(d_{i}\right)$ of a interfacial tension, $\mathbf{b}$ aqueous contact angle and $\mathbf{c}$ aqueous viscosity to the oil recovery (\%OOIP) as an assessing indicator 


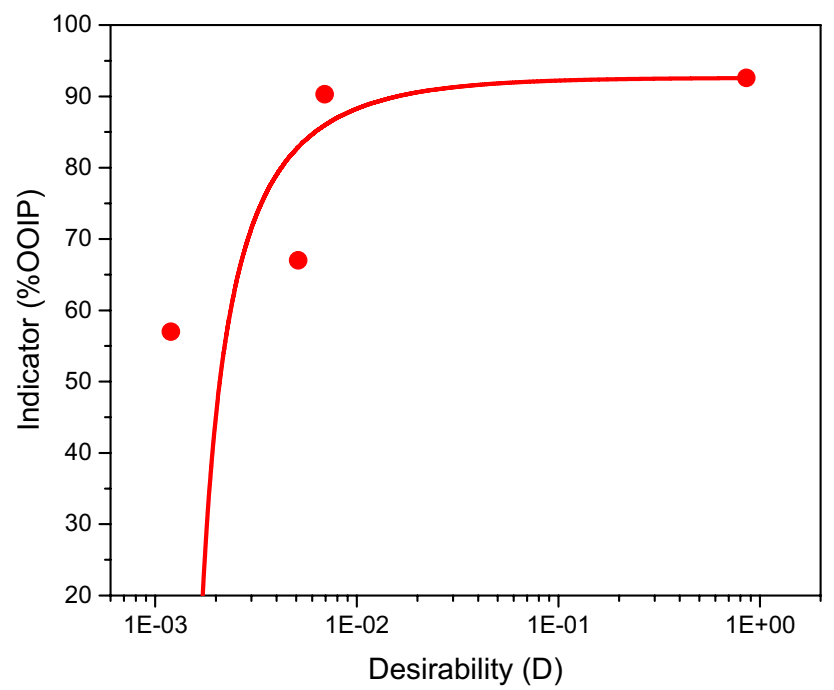

Fig. 3 Desirability $(D)$ combined from three affecting factors to the oil recovery (\%OOIP) as an assessing indicator. The line is nonlinear curve fit with $R^{2}=0.7212$

to correlate with the oil recovery (in form of recovery factor). Four pore volumes of prepared microemulsion were continuously flooded through the reconstructed sandpack to achieve the tertiary oil recovery. 160 data sets of various oilaqueous IFTs and the recovery factor (RF) were successfully correlated in the authors' work (Jeirani et al. 2013).

In addition to Jeirani et al. (2013), the IFTs of all interfaces (i.e. oil-aqueous, aqueous-solid and oil-solid) are calculated following the method used by (Pashley and Israelachvili 1981). The surface contact angle is assumed to be $80^{\circ}$ which is categorised as an intermediate wet. To analyse the desirability, these three IFTs are the effecting factors of the model while the recovery factor (RF) is the indicator. The oil-aqueous and aqueous-solid IFTs are desirable factors whereas the oil-solid IFT is undesirable factor, then the factor fractions $\left(X_{i}\right)$ are calculated according to Eqs. (4) and (5) respectively.

The lowest and the highest values of each affecting factor are assigned to be the reported value range of each factor, then the lower and the upper limit values of the satisfied interval $\left(S_{0}\right.$ and $\left.S_{1}\right)$ can be calculated similarly to the previous example. Therefore, the Harrington's desirability function $\left(d_{i}\right)$ is calculated according to Eq. (3) for each factor and plotted against the recovery factor (RF) shown in Fig. 5. The combined desirability $(D)$ plotted in Fig. 6 is used to correlate the recovery factor $(\mathrm{RF})$ to assess the affecting factors.

Every individual desirability $\left(d_{i}\right)$ of all three effecting factors is correlated perfectly by the logarithm function (Fig. 5). The combined desirability $(D)$ is also found a good logarithm correlation with the recovery factor (RF). This agrees to the conclusion by Jeirani et al. (2013) that the oil-aqueous IFT correlates to the oil recovery factor. It should be noted that the combined desirability $(D)$ has slightly lower $R^{2}$ than the individual desirability $\left(d_{i}\right)$ although it is higher than 0.9 indicating a very good fitting. The reason could be explained that the summation of individual desirability $\left(d_{i}\right)$ makes the combined desirability $(D)$ dispersed or scattered because the individual desirability $\left(d_{i}\right)$ is calculated from different value ranges. In addition, this example demonstrates that the desirability model is clearly able to predict the trend or indicate the relationship of the IFTs and the recovery factor (i.e. the oil recovery).

\section{Zhou et al. (2000)}

Zhou et al. (2000) measured the oil recovery from sandstones by spontaneous imbibition and waterflooding and studied the relationship between oil recovery and various wettability parameters (i.e. aqueous contact angle, Amott index and work of imbibition). The work also reported other rock properties of the core sample (i.e. permeability and water saturation) which are analysed in addition to the wettability parameters to examine the proposed model.

There are five effecting factors in this test including the modified Amott index $\left(I^{\prime}{ }_{w}\right)$, relative pseudowork of imbibition $\left(W_{R}\right)$, cosine of aqueous contact angle $(\cos \theta)$, gas and brine permeabilities $\left(k_{g}\right.$ and $\left.k_{b}\right)$ and initial water saturation $\left(S_{\mathrm{wi}}\right)$. The oil recovery (\%OOIP) is the indicator similar to the previous trails. Modified Amott index $\left(I_{w}^{\prime}\right)$, relative pseudowork of imbibition $\left(W_{R}\right)$, cosine of aqueous contact angle $(\cos \theta)$, gas and brine permeabilities $\left(k_{g}\right.$ and $\left.k_{b}\right)$ are desirable factors which promote the oil release from rock surface or enhance the oil flow in the porous media. On the contrary, initial water saturation $\left(S_{\mathrm{wi}}\right)$ is undesirable factor because the higher the initial water saturation implies the lower the initial oil saturation in the core. Equations (4) and (5) are then used to calculate the factor fractions $\left(X_{i}\right)$ for the desirable and undesirable factors, respectively.

The value range of each factor is used as the lowest and the highest values for each effecting factor allowing the lower and the upper limit values of the satisfied interval $\left(S_{0}\right.$ and $\left.S_{1}\right)$ calculated. Then, the desirability function $\left(d_{i}\right)$ of every factor can be determined (Eq. 3). The relationship between the individual desirability $\left(d_{i}\right)$ and the oil recovery (\%OOIP) is shown in Fig. 7. The combined desirability $(D)$ is also plotted in Fig. 8 including the combined desirability without $k_{g}, k_{b}$ and $S_{\mathrm{wi}}\left(D^{*}\right)$.

The $I_{w}^{\prime}$ has a linear relationship to the oil recovery clearly as shown in Fig. 7a. The recovery methods are also able to distinguish the difference of the plots. For the waterflooding (WF), the oil recovery is relatively high at low $d_{i}$ and slightly decreases as the $d_{i}$ increases. For the spontaneous imbibition (SI) and waterflooding after spontaneous imbibition $(\mathrm{WF}+\mathrm{SI})$, the data trend is coupled linearly and increases as a function of \%OOIP. Figure $7 \mathrm{~b}$, the $W_{R}$ has a fair correlation 

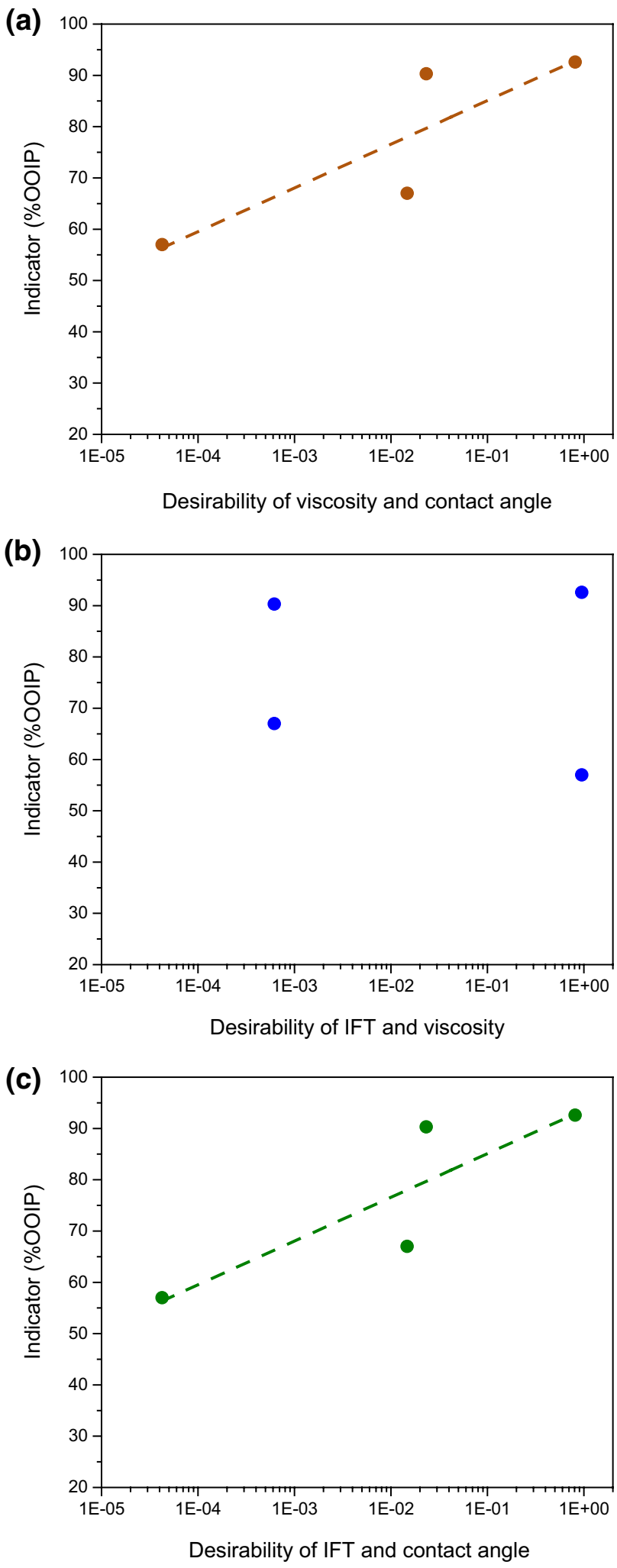

Fig. 4 Duo-desirability (combined from only two affecting factors) to the oil recovery (\%OOIP) as an assessing indicator: a without interfacial tension, $\mathbf{b}$ without contact angle and $\mathbf{c}$ without viscosity. The lines in $\mathbf{a}$ and $\mathbf{c}$ are linearly fitted with the same $R^{2}=0.7454$ in form of curve. For WF, the \%OOIP is higher at low $d_{i}$ and decreases slightly at the higher $\mathrm{d}_{\mathrm{i}}$ before becomes constant at about $0.4-0.5 d_{i}$. The \%OOIP increases massively at low $d_{i}$ in SI and WF + SI cases, and then the \%OOIP is constant suddenly from $0.2 d_{i}$. Similarly to $\cos \theta$ at Fig. 7c, the $\cos \theta$ has relatively the same relation with $W_{R}$ and the difference of the recovery methods is exactly the same. On the contrary, the $k_{g}$ and $k_{b}$ have no relations with \%OOIP at all due to Fig. $7 \mathrm{~d}$. The reason might be since they are not the wettability properties and actually refer to the flow ability of the fluids in the porous media which do not relate to the oil detachment from the surface or recovery from the rock. In addition, the permeabilities reported in the experiment have the same magnitude and about the same value but the \%OOIP strongly scatters, supporting that they are \%OOIP unrelated in this study. The recovery methods cannot distinguish or imply any of such relationship as well in case of permeabilities. The plot also scatters in the Fig. 7e of $S_{\text {wi }}$. Although the \%OOIP and $d_{i}$ relationship cannot be indicated, the recovery methods could imply that the WF always contributes higher \%OOIP than SI and WF + SI methods in case of the $S_{\text {wi }}$. However, the relationship of this effecting factor cannot be confirmed.

Figure 8 a shows the plot of combined desirability $(D)$ against the \%OOIP revealing the form of its correlation curve-\%OOIP is low at low $D$ and then stable shortly after the \%OOIP changed. The recovery methods are crucial here. The WF got the higher \%OOIP while others have it lower. The WF increases at the beginning of a short period of time and then drops before stable while the SI and WF + SI begin at relatively low \%OOIP then increase before stable. Interestingly, the plot is smoother and obtains more obvious correlation when combined only some selected $d_{i}$ (called $D^{*}$-combined without $k_{g}, k_{b}$ and $S_{\text {wi }}$ ) shown in Fig. 8b. It is noted that the $D^{*}$ only includes the wettability parameters which reasonably are the main factors affecting the oil recovery. This summary agrees to the conclusion from the original study by Zhou et al. (2000) that the oil recovery is highly sensitive to the wettability.

\section{Discussions on effectiveness and limitation of the model}

Since the proposed model analyses the experiment data through the desirability function in order to re-scale the raw data to be the same, the calculation and analysis do not use any of the theoretical equations. This would bring the analysed results having some limitations although its advantages are obvious. The followings are main advantageous effectivenesses and some limitations of the model.

According to the examined cases, the method to evaluate the effecting factors on the oil recovery by using the 

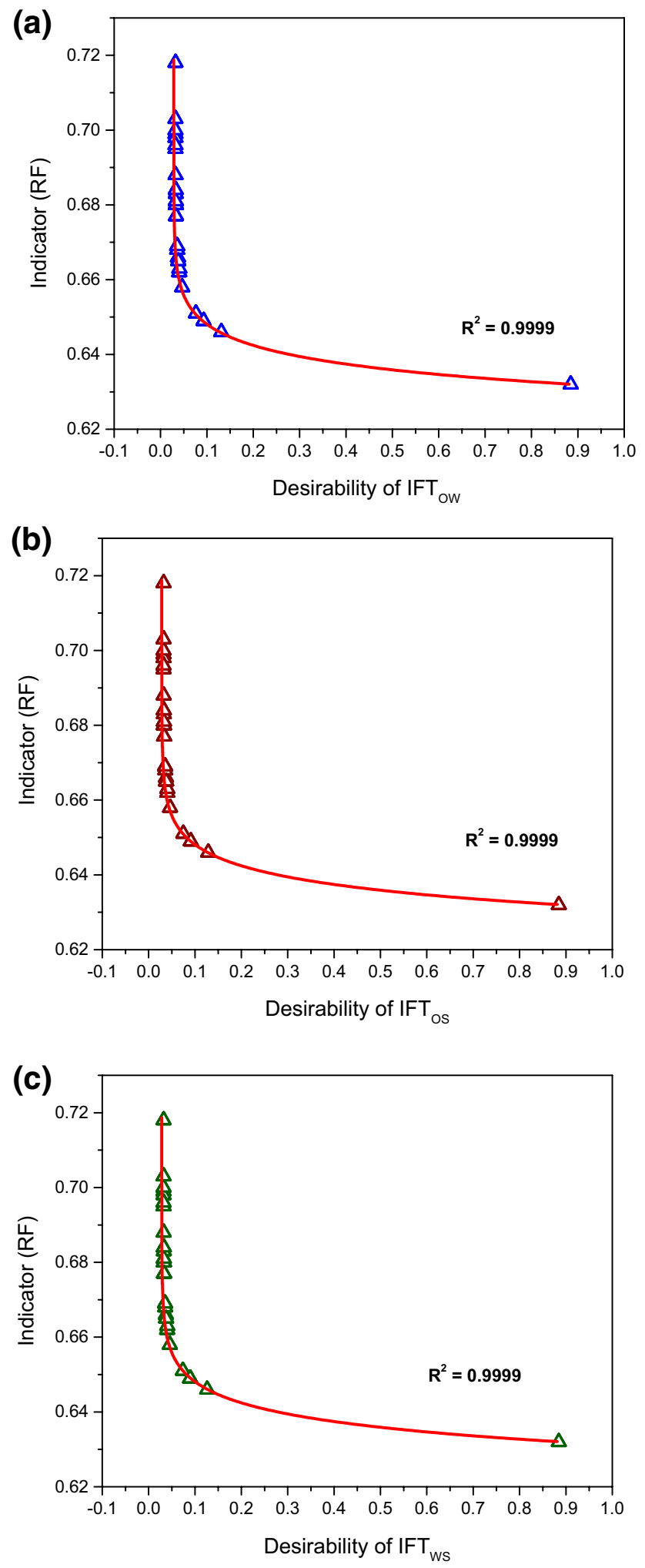

Fig. 5 Individual desirability $\left(d_{i}\right)$ of a oil-aqueous interfacial tension, b oil-solid interfacial tension and c solid-aqueous interfacial tension to the recovery factor (RF) as an assessing indicator. All lines are exponential curve fit

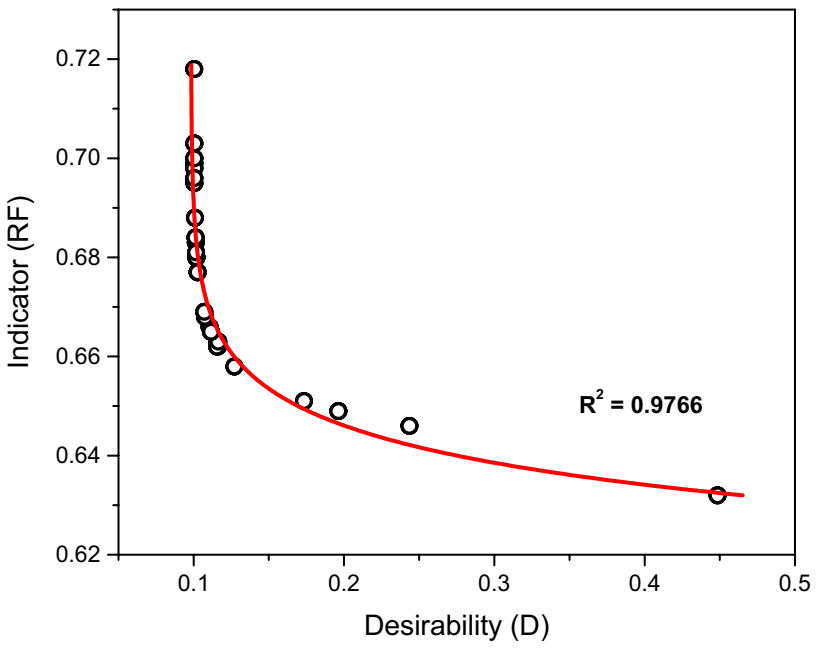

Fig. 6 Desirability $(D)$ combined from three affecting factors to the recovery factor $(\mathrm{RF})$ as an assessing indicator. The line is exponential curve fit

desirability function has shown the ability to separate the contribution of each factor to the oil recovery. The plot from the analysis does not only indicate whether the factors do contribute but also reveal that which factor contribute dominantly to the oil recovery. Separation of the factor's contribution is more worth when the considered factors are related to each other, such as contact angle and IFT in Young's equation, thus the actual effect on the oil recovery of every single factor is able to be individually considered. Moreover, the desirability plot could potentially construct a relationship between factors and indicator if the perfect correlation is achieved. The obtained correlation can be used as an empirical equation to predict the trend of results and also emphasis the oil recovery mechanisms.

On the contrary, the model needs to know that each effecting factor is desirable or undesirable to the indicator (the oil recovery) before the data is analysed. This limitation means that a good understanding or a solid knowledge on the studied topic has to be available in order to state the desirability of each factor. The desirability model will only enhance further analyses and advance discussions but not the preliminary works or fundamental determinations. Other limitation is that the model needs a relatively high number of the data sets for the reliable analysis. The proposed method uses the data to obtain the statistical correlation. A small number of data sets could result in a poor correlation, subsequently leading to the wrong conclusion. The previous cases of Almansour et al. (2017) and Jeirani et al. (2013) works are the good examples. The former has a relatively low number of data sets (4 data) having a low $R^{2}$ correlation while the latter has a relatively high number of data sets (160 data) leading to achieve an obvious fitting with high $R^{2}$. 
Fig. 7 Individual desirability $\left(d_{i}\right)$ of a modified Amott index $\left(I_{w}^{\prime}\right)$, b relative pseudowork of imbibition $\left(W_{R}\right)$, c cosine of aqueous contact angle $(\cos \theta)$, $d$ gas and brine permeabilities $\left(k_{g}\right.$ and $\left.k_{b}\right)$ and $\mathbf{e}$ initial water saturation $\left(S_{\mathrm{wi}}\right)$ to the oil recovery (\%OOIP) as an assessing indicator. The data are shown in three set of recovery methods including waterflooding (WF: hallow square), spontaneous imbibition (SI: solid circle) and waterflooding after spontaneous imbibition completed (WF + SI: hallow circle)
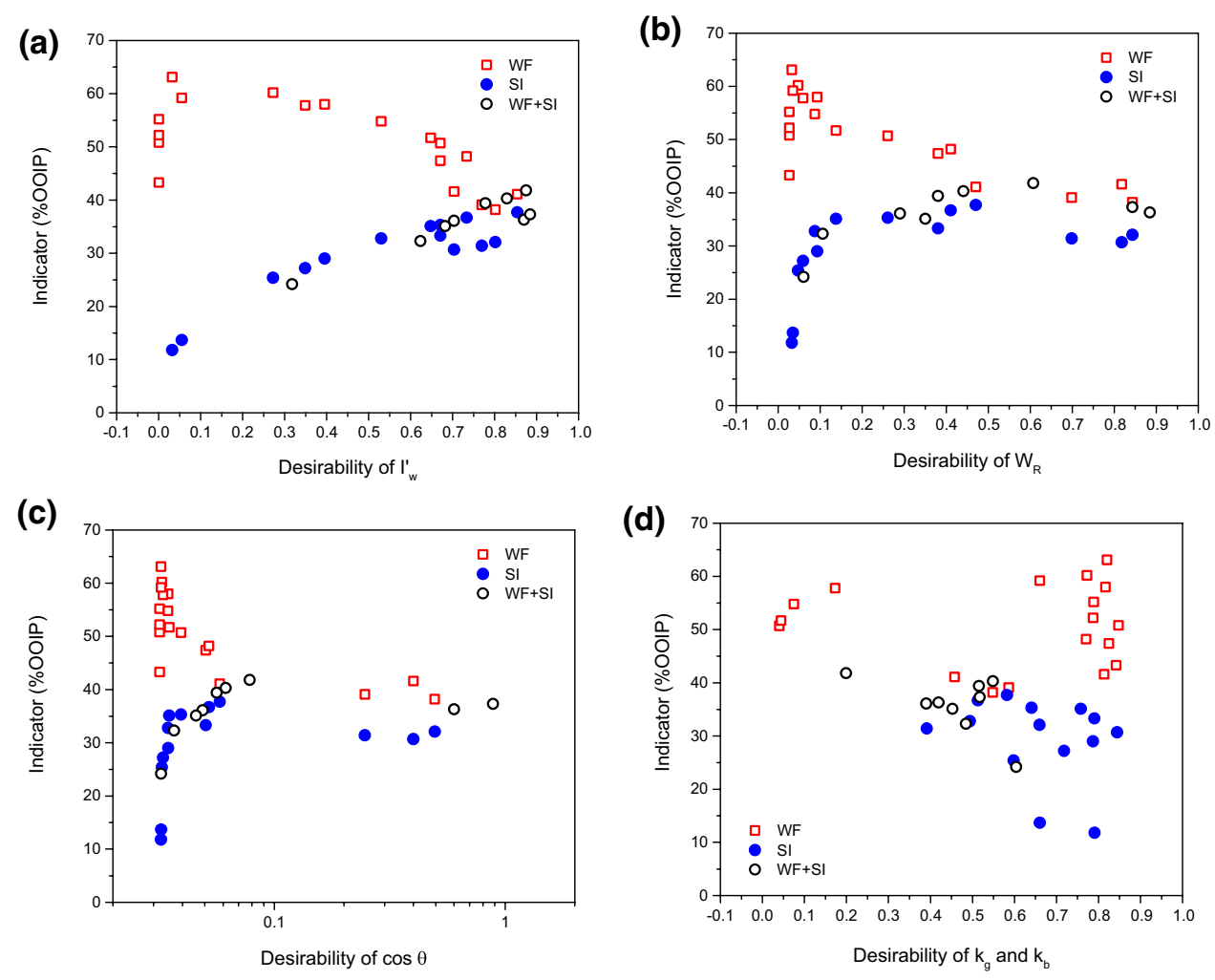

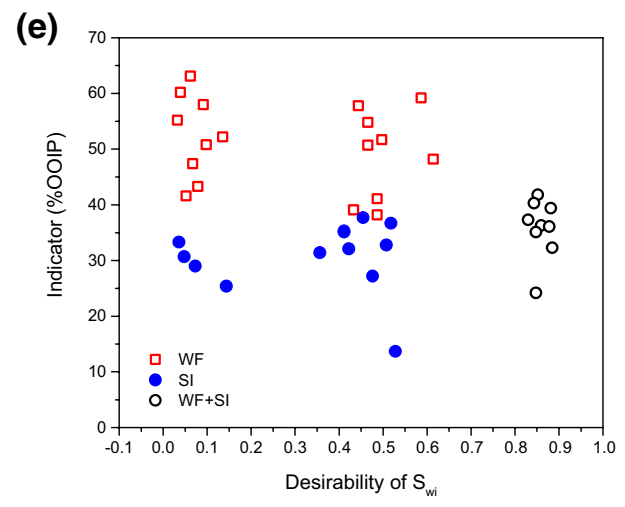

\section{Conclusion}

The desirability function has been proposed to re-scale all of related factors to the oil recovery (i.e. indicator) and consequently combines all factors using the Harrington's function. Then, the factors become only a single parameter that correlates with the oil recovery. The model principally aims to indicate the dominant factor affecting the oil recovery out of all factors. The result could be able to predict a trend of the factors-and-indicator if a good correlation is achieved.

Three published works of coreflooding tests were examined which showed a practical application. The first correlation according to the experiment of Almansour et al. (2017) implies that the oil recovery is affected by IFT, contact angle and oil viscosity after the data has been analysed using the combined desirability. By separating one of the three factors, the contact angle was found to dominantly govern the oil recovery which agrees with in the authors' conclusion. A number of Jeirani et al. (2013) data sets have also been demonstrated a good correlation between the factors and the oil recovery, allowing to predict the relationship trend. The third study of Zhou et al. (2000) clearly showed a good model application because the analysed plots imply a similar conclusion of the authors' original work that the oil recovery is sensitive to the wettability.

Although the desirability model can separate the contribution of each factor and could potentially construct an empirical relationship, there are some limitations of the model use. A good understanding or a solid knowledge on the studied subject needs to be available because it is used to state the effecting factors whether desirable or undesirable to the oil 

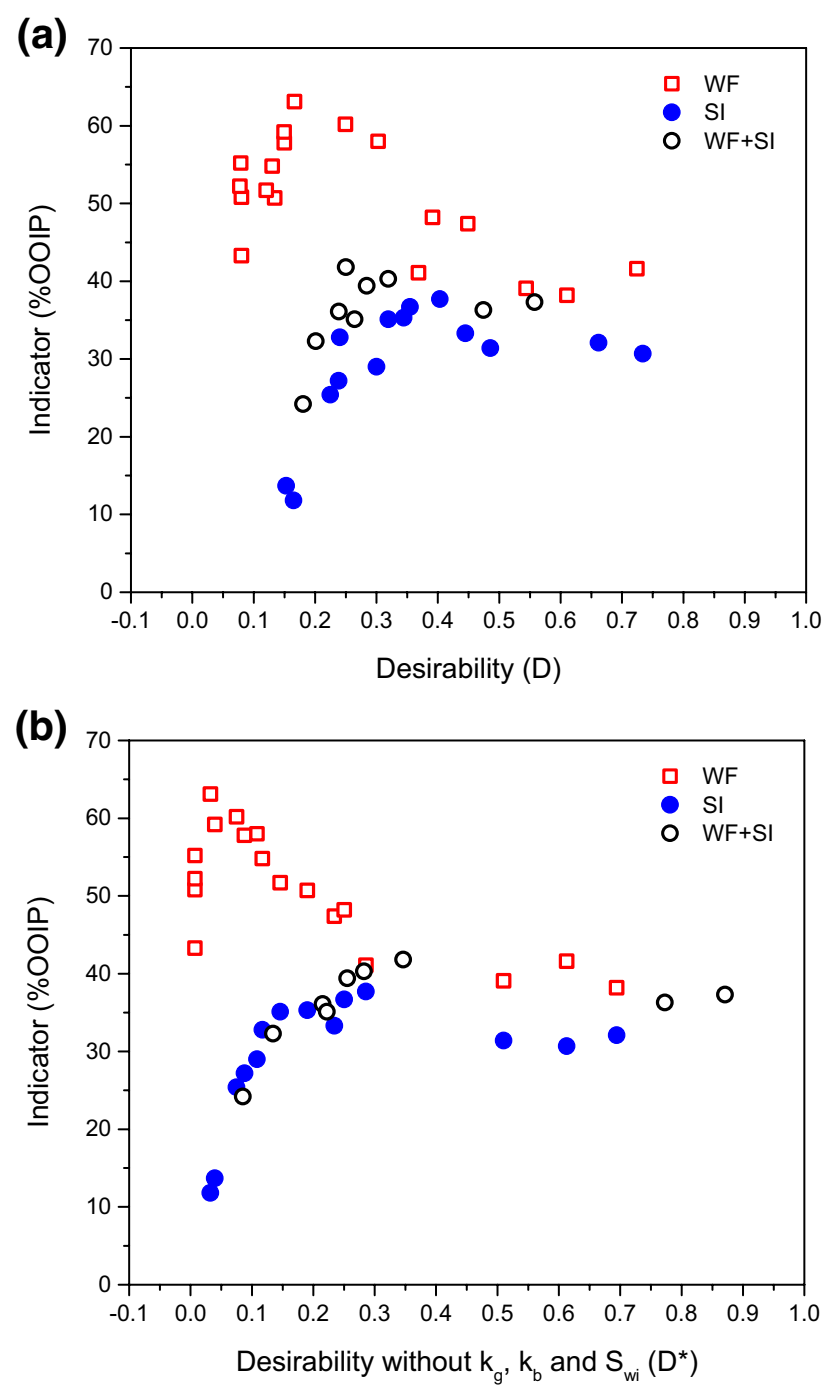

Fig. 8 Desirability combined from the affecting factors: a combined desirability $(D)$ of all effecting factors $\left(I_{w}^{\prime}, W_{R}, \cos \theta, k g, k_{b}\right.$ and $\left.S_{\text {wi }}\right)$ and $\mathbf{b}$ combined desirability $\left(D^{*}\right)$ of all effecting factors without gas and brine permeabilities and initial water saturation $\left(k_{g}, k_{b}\right.$ and $\left.S_{\mathrm{wi}}\right)$ to the oil recovery (\%OOIP) as an assessing indicator. The data are shown in three set of recovery methods including waterflooding (WF: hallow square), spontaneous imbibition (SI: solid circle) and waterflooding after spontaneous imbibition completed (WF + SI: hallow circle)

recovery before the model is calculated. The need of a high number of data sets to be analysed is the other main limitation.

Open Access This article is distributed under the terms of the Creative Commons Attribution 4.0 International License (http://creativeco mmons.org/licenses/by/4.0/), which permits unrestricted use, distribution, and reproduction in any medium, provided you give appropriate credit to the original author(s) and the source, provide a link to the Creative Commons license, and indicate if changes were made.

\section{Appendix: Calculations of Almansour et al.'s case}

\section{Calculation of the lower and the upper limit values of the satisfied interval $\left(S_{0}\right.$ and $\left.S_{1}\right)$}

Let the satisfied interval ranges between 0.40 and 0.60 according to Fig. 1. Then, the lower and upper limit values of the satisfied interval $\left(S_{0}\right.$ and $\left.S_{1}\right)$ are:

$S_{0}=[($ maximum value of the factor - minimum value of the factor $) \times 0.40]$

+ minimum value of the factor and

$S_{1}=[($ maximum value of the factor - minimum value of the factor $) \times 0.60]$

+ minimum value of the factor

Factor: oil-aqueous IFT (use the value range of $44.4-53.0 \mathrm{mN} / \mathrm{m}$ )

$S_{0}=[(53.0-44.4) \times 0.40]+44.4=\mathbf{4 7 . 8 4} \mathrm{mN} / \mathrm{m}$ and

$S_{1}=[(53.0-44.4) \times 0.60]+44.4=\mathbf{4 9 . 5 6} \mathrm{mN} / \mathrm{m}$

Factor: aqueous contact angle (use the value range of $\left.65.1^{\circ}-90.3^{\circ}\right)$

$S_{0}=[(90.3-65.1) \times 0.40]+65.1=\mathbf{7 5 . 1 8}^{\circ}$ and

$S_{1}=[(90.3-65.1) \times 0.60]+65.1=\mathbf{8 0 . 2 2}^{\circ}$

Factor: oil viscosity (use the value range of $0.64-0.73 \mathrm{cP}$ )

$S_{0}=[(0.73-0.64) \times 0.40]+0.64=\mathbf{0 . 6 7 6} \mathbf{~} \mathbf{P}$ and

$S_{1}=[(0.73-0.64) \times 0.60]+0.64=\mathbf{0 . 6 9 4} \mathbf{c P}$

\section{Calculation of factor fractions $\left(\mathbf{X}_{\mathbf{i}}\right)$}

Desirable Factor: oil-aqueous IFT

According to Eq. (4),

$X_{\mathrm{IFT}}^{D}=\frac{S_{i}-47.84}{49.56-47.84}$

And substituting $S_{i}$ by the oil-aqueous IFT values, then the factor fractions $\left(X_{\mathrm{IFT}}^{D}\right)$ are:

\begin{tabular}{lr}
\hline $\mathrm{S}_{\mathrm{i}}$ (oil-aqueous IFT, $\left.\mathrm{mN} / \mathrm{m}\right)$ & $X_{\mathrm{IFT}}^{D}$ \\
\hline 44.4 & -2.0 \\
53.0 & 3.0 \\
\hline
\end{tabular}

Undesirable factor: aqueous contact angle

According to Eq. (5), 
$X_{\theta}^{U}=\frac{75.18-S_{i}}{80.22-75.18}$

And substituting $S_{i}$ by the aqueous contact angle values, then the factor fractions $\left(X_{\theta}^{D}\right)$ are:

\begin{tabular}{lr}
\hline $\mathrm{S}_{\mathrm{i}}\left(\right.$ aqueous contact angle, $\left.{ }^{\circ}\right)$ & \multicolumn{1}{c}{$X_{\theta}^{D}$} \\
\hline 65.1 & 2.00 \\
70.1 & 1.01 \\
75.4 & -0.04 \\
90.3 & -3.00 \\
\hline
\end{tabular}

Desirable factor: oil viscosity

According to Eq. (4),

$X_{\mu}^{D}=\frac{S_{i}-0.676}{0.694-0.676}$

And substituting $S_{i}$ by the oil viscosity values, then the factor fractions $\left(X_{\mu}^{D}\right)$ are:

\begin{tabular}{lr}
\hline $\mathrm{S}_{\mathrm{i}}$ (oil viscosity, $\left.\mathrm{cP}\right)$ & \multicolumn{1}{c}{$X_{\mu}^{D}$} \\
\hline 0.64 & -2.0 \\
0.73 & 3.0 \\
\hline
\end{tabular}

\section{Calculation of individual and combined desirability $\left(d_{i}\right.$ and $\left.D\right)$}

According to Eq. (3), the individual desirability $\left(d_{i}\right)$ of each effecting factor is calculated by substituting its factor fraction $\left(X_{i}\right)$ using the Harrington's function according to Eq. (3):

Factor: oil-aqueous IFT

$d_{\mathrm{IFT}}=e^{-e^{-x_{\mathrm{IFT}}}}$

\begin{tabular}{lrl}
\hline $\mathrm{S}_{\mathrm{i}}($ oil-aqueous IFT, $\mathrm{mN} / \mathrm{m})$ & \multicolumn{1}{c}{$X_{\mathrm{IFT}}^{D}$} & \multicolumn{1}{l}{$d_{\mathrm{IFT}}$} \\
\hline 44.4 & -2.0 & $6.18 \times 10^{-4}$ \\
53.0 & 3.0 & $9.51 \times 10^{-1}$ \\
\hline
\end{tabular}

Factor: aqueous contact angle

\begin{tabular}{lrl}
$d_{\theta}=e^{-e^{-X_{\theta}}}$ & \\
\hline$S_{i}\left(\right.$ aqueous contact angle, $\left.{ }^{\circ}\right)$ & \multicolumn{1}{c}{$X_{\theta}^{D}$} & $d_{\theta}$ \\
\hline 65.1 & 2.00 & $8.73 \times 10^{-1}$ \\
70.1 & 1.01 & $6.94 \times 10^{-1}$ \\
75.4 & -0.04 & $3.52 \times 10^{-1}$ \\
90.3 & -3.00 & $1.89 \times 10^{-9}$ \\
\hline
\end{tabular}

Factor: oil viscosity

$d_{\mu}=e^{-e^{-x_{\mu}}}$

تودينة الملك عبدالعزيز

KACST مبليد

\begin{tabular}{lrl}
\hline $\mathrm{S}_{\mathrm{i}}$ (oil viscosity, cP) & \multicolumn{1}{c}{$X_{\mu}^{D}$} & \multicolumn{1}{l}{$d_{\mu}$} \\
\hline 0.64 & -2.0 & $6.18 \times 10^{-4}$ \\
0.73 & 3.0 & $9.51 \times 10^{-1}$
\end{tabular}

\section{References}

Almansour AO, AlQuraishi AA, AlHussinan SN, AlYami HQ (2017) Efficiency of enhanced oil recovery using polymer-augmented low salinity flooding. J Pet Explor Prod Technol. https://doi. org/10.1007/s13202-017-0331-5

Anderson WG (1987) Wettability literature survey.6. The effects of wettability on waterflooding. J Pet Technol 39:1605-1622. https ://doi.org/10.2118/16471-pa

Choi SK, Son HA, Kim HT, Kim JW (2017) Nanofluid enhanced oil recovery using hydrophobically associative zwitterionic polymercoated silica nanoparticles. Energy Fuels 31:7777-7782. https:// doi.org/10.1021/acs.energyfuels.7b00455

Harrington E (1965) The desirability function. Industrial quality control 21:494-498

Hu ZL, Haruna M, Gao H, Nourafkan E, Wen DS (2017) Rheological properties of partially hydrolyzed polyacrylamide seeded by nanoparticles. Ind Eng Chem Res 56:3456-3463. https://doi. org/10.1021/acsiecr.6b05036

Jamaloei BY (2015) The effect of interfacial tension on two-phase relative permeability: a review. Energy Sour Part A: Recovery, Utilization, Environ Effects 37:245-253. https://doi.org/10.1080/15567 036.2011.557708

Jeirani Z, Jan BM, Ali BS, Noor IM, See CH, Saphanuchart W (2013) Correlations between interfacial tension and cumulative tertiary oil recovery in a triglyceride microemulsion flooding. J Ind Eng Chem 19:1310-1314. https://doi.org/10.1016/j.jiec.2012.12.033

Jiang YH, Xu W, Choi CH (2016) Effects of particulates on contact angles and adhesion of a droplet: a critical review. Rev Adhes Adhes 4:192-222. https://doi.org/10.7569/raa.2016.097306

Mason G, Fischer H, Morrow NR, Ruth DW (2010) Correlation for the effect of fluid viscosities on counter-current spontaneous imbibition. J Pet Sci Eng 72:195-205. https://doi.org/10.1016/j.petro 1.2010.03.017

Nikolaev VF et al (2017) Integral extraction-wettability criteria of the effectiveness of industrial solvents used for enhanced oil recovery. Pet Sci Technol 35:851-855. https://doi.org/10.1080/10916 466.2017.1279177

Pashley RM, Israelachvili JN (1981) A comparison of surface forces and interfacial properties of mica in purified surfactant solutions. Colloids Surf 2:169-187. https://doi.org/10.1016/01666622(81)80006-6

Young T (1805) An essay on the cohesion of fluids. Philos Trans R Soc Lond 95:65-87

Zhou XM, Morrow NR, Ma SX (2000) Interrelationship of wettability, initial water saturation, aging time, and oil recovery by spontaneous imbibition and waterflooding. SPE J 5:199-207. https://doi. org/10.2118/62507-pa

Publisher's Note Springer Nature remains neutral with regard to jurisdictional claims in published maps and institutional affiliations. 